\title{
Readiness for Change Ditinjau dari Kepemimpinan Transformasional Pada Karyawan/I PT. Mam Medan
}

\author{
Chaterine, Sri Hartini, Winida Marpaung
}

Fakultas Psikologi Universitas Prima Indonesia Medan

email: chaterine_xu@yahoo.com, srihartini_psikologi@unpri.mdn.ac.id, winida.marpaung@gmail.com

\begin{abstract}
Abstrak
Penelitian ini bertujuan untuk mengetahui hubungan antara kepemimpinan transformasional dengan readiness for change. Hipotesis yang diajukan dalam penelitian ini adalah ada hubungan positif antara kepemimpinan transformasional dengan readiness for change. Subjek penelitian yang digunakan pada penelitian ini adalah karyawan/i PT. Mega Anugrah Mandiri Medan sebanyak 120 orang. Data diperoleh dari skala untuk mengukur readiness for change dan kepemimpinan transformasional. Perhitungan dilakukan dengan melakukan uji prasyarat analisis (uji asumsi) yang terdiri dari uji normalitas sebaran, dan uji linearitas hubungan. Analisis data yang digunakan adalah menggunakan korelasi Product Moment melalui bantuan SPSS 20 for Windows. Hasil analisis data menunjukkan koefisien korelasi sebesar $0.571(p<0.05)$. Ini menunjukkan bahwa adanya hubugan positif antara kepemimpinan transformasional dengan readiness for change. Hasil penelitian ini menunjukkan bahwa sumbangan yang diberikan variabel kepemimpinan transformasional terhadap readiness for change adalah sebesar 32.6 persen, selebihnya 67.4 persen di pengaruhi oleh faktor lain yang tidak diteliti. Berdasarkan hasil penelitian ini dapat ditarik kesimpulan bahwa hipotesis penelitian ada hubungan positif antara kepemimpinan transformasional dengan readiness for change dapat diterima.
\end{abstract}

Kata kunci: kepemimpinan transformasional, readiness for change

\section{Readiness for Change Viewed From Transformational Leadership on the Employee Of PT. Mam Medan}

\begin{abstract}
This study aims to determine the relationship between transformational leadership and readiness for change. The hypothesis of this study states that there is a positive relationship between transformational leadership and readiness for change. Subjects of this study were 120 employee of PT. Mega Anugrah Mandiri at Medan, North Sumatra. Data were obtained from a scale to measure transformational leadership and readiness for change. The calculation was performed using test requirements analysis (assumption), which consists of normality distribution test and linearity relationship test. Data were analyze by Product Moment Correlation with SPSS 20 for windows. The results of data analysis showed that the correlation coefficient was $0.571(p<0.05)$. It showed that there is a positive relationship between transformational leadership and readiness for change. These results indicate that the contributions of transformational leadership variable to readiness for change was at 32.6 percent, while the remaining 67.4 percent is influenced by other factors not examined. From these results it is concluded that the hypothesis stating there is a positive relationship between transformational leadership and readiness for change, is acceptable.
\end{abstract}

Keywords: transformational leadership, readiness for change

\section{Pendahuluan}

Zaman

globalisasi yang terus

berkembang membuat suatu organisasi harus mampu mengikuti perubahan yang terjadi agar bisa mencapai tujuan atau sasaran yang ingin dicapai. Organisasi merupakan sekelompok orang yang memiliki saling ketergantungan satu sama lainnya, yang secara bersamasama memfokuskan usaha mereka untuk mencapai tujuan, atau menyelesaikan tugas tertentu (Mulyadi, 2007). Kesuksesan suatu organisasi sangat ditentukan oleh kemampuan 
organisasi untuk beradaptasi terhadap perubahan lingkungan strategis dalam berbagai dimensi. Perubahan lingkungan strategis ini dapat menjadi sumber masalah apabila organisasi terlambat beradaptasi dan mengambil langkah strategis yang tepat. Sebuah organisasi yang mampu beradaptasi secara berkelanjutan dengan tuntutan perubahan lingkungan bisnis akan maju dan berkembang. Sebaliknya, organisasi yang tidak mampu beradaptasi dengan perubahan lingkungan strategis akan mengalami kemunduran, bahkan kebangkrutan (Ancok, 2012).

Sims, (2002) mengatakan bahwa salah satu upaya dalam meningkatkan keunggulan kompetitif perusahaan adalah meningkatkan perhatian pemimpin terhadap orang-orang yang bekerja dalam organisasi yang ia pimpin. Pemimpin harus mampu memberikan arahan yang tepat kepada bawahannya, memberikan motivasi, dan dukungan kepada bawahannya agar siap dalam melakukan perubahan yang tepat dan cepat sehingga tujuan perusahaan dapat tercapai. Perubahan yang dimaksud adalah readiness for change.

MenurutArmenakis, dkk., (dalam Russell \& Russel, 2006), readiness for change adalah keadaan kognitif yang terjadi ketika anggota organisasi memiliki sikap, kepercayaan, dan niat positif terhadap perubahan tersebut. Senada dengan itu, Holt, (2007) mengemukakan bahwa readiness for change ini didefinisikan sebagai sikap komprehensif yang secara simultan dipengaruhi oleh isi, proses, konteks dan individu yang terlibat dalam suatu perubahan. Kesiapan secara kolektif merefleksikan sejauh mana kecenderungan individu untuk menyutujui, menerima, dan mengadopsi rencana spesifik yang bertujuan untuk mengubah keadaan saat ini.
Berdasarkan beberapa pendapat dan batasan yang dikemukakan oleh para ahli di atas, dapat di buat kesimpulan bahwa readiness for change merupakan suatu proses perubahan yang terjadi pada seseorang yang harus siap dan mampu untuk menjalani atau menghadapi segala perubahan yang terjadi pada suatu organisasi. Kesiapan untuk berubah menjadi faktor yang penting bagi kesuksesan perubahan suatu organisasi.

Armenakis dan Harris, mengemukakan adanya lima dimensi yang dapat merubah keyakinan diri karyawan untuk mendukung perubahan, yaitu (1) Discrepancy, yaitu keyakinan bahwa perubahan itu diperlukan oleh organisasi; (2) Appropriateness, yaitu adanya keyakinan bahwa perubahan spesifik yang dilakukan merupakan cara yang tepat untuk mengatasi masalah yang dihadapi; (3) Efficacy, yaitu rasa kepercayaan bahwa karyawan dan organisasi mampu mengimplementasikan perubahan; (4) Principal Support, yaitu persepsi bahwa organisasi memberikan dukungan dan berkomitmen dalam pelaksanaan perubahan dan menyukseskan perubahan organisasi; dan (5) Personal Valence, yaitu rasa keyakinan bahwa perubahan akan memberikan keuntungan personal pada karyawan.

Readiness for Change seseorang dipengaruhi oleh berbagai faktor. Salah satu faktor yang paling sering ditemui adalah pentingnya peranan seorang pemimpin yang mampu membuat karyawannya untuk mampu mengikuti perubahan yang terjadi, yaitu kepemimpinan transformasional. Penelitian yang dilakukan oleh Abbasi (2017) pada karyawan perusahaan Gilan membuktikan bahwa salah satu faktor yang mempengaruhi readiness for change adalah kepemimpinan transformasional. Hasil penelitian menunjukkan kepemimpinan 
transformasional secara signifikan dan positif berpengaruh terhadap readiness for change. Artinya semakin baik kepemimpinan transformasional di suatu perusahaan maka readiness for change akan semakin baik pula.

Burns (dalam Northouse, 2013), kepemimpinan transformasional merupakan proses di mana orang terlibat dengan orang lain, dan menciptakan hubungan yang meningkatkan motivasi dan moralitas dalam diri pemimpin dan pengikut. Sementara itu, Greenberg dan Baron (dalam Pramudianto, 2015) mendefinisikan kepemimpinan transformasional sebagai suatu perilaku kepemimpinan yang dengannya seorang pemimpin menggunakan kharismanya untuk mentransformasi dan merevitalisasi organisasi.

Berdasarkan pendapat di atas, dapat disimpulkan bahwa kepemimpinan transformasional adalah kepemimpinan yang memiliki sifat sosial, memiliki visi, mampu menginpirasi dan peduli dengan bawahannya, serta menciptakan hubungan yang meningkatkan motivasi serta moralitas dalam diri pemimpin dan pengikut.

Robbins dan Judge (2007) mengemukakan bahwa aspek-aspek kepemimpinan transformasional adalah (1) Pengaruh yang Ideal, yaitu Memberikan visi dan misi, menanamkan kebanggaan, serta mendapatkan respek dan kepercayaan; (2) Motivasi yang Inspirasional, yaitu Mengomunikasikan ekspektasi yang tinggi, menggunakan simbol-simbol untuk berfokus pada upaya, dan menyatakan tujuan-tujuan penting secara sederhana; (3) Stimulasi Intelektual, yaitu Meningkatkan kecerdasan, rasionalitas, dan pemecahan masalah yang cermat; dan (4) Pertimbangan yang Bersifat Individual, yaitu Memberikan perhatian pribadi, memperlakukan masing-masing karyawan, secara individual, serta melatih dan memberikan saran.

Berdasarkan hasil kajian literatur yang ada, terdapat beberapa penelitian dan ahli yang telah melakukan penelitian untuk menunjukkan bahwa kepemimpinan transformasional mempengaruhi readiness for change. Salah satu hasil penelitian yang dilakukan oleh Pranowo, dkk., (2016). Hasil penelitiannya menunjukkan bahwa terdapat hubungan positif yang signifikan antara kepemimpinan transformasional dengan readiness for change, sedangkan penelitian yang dilakukan oleh Abbasi (2017) juga membuktikan bahwa salah satu faktor yang mempengaruhi readiness for change adalah kepemimpinan transformasional. Hasil penelitian menunjukkan kepemimpinan transformasional secara signifikan dan positif berpengaruh terhadap readiness for change. Artinya semakin baik kepemimpinan transformasional di suatu perusahaan maka readiness for change akan semakin baik pula.

Selain kepemimpinan transformasional, readiness for change juga di pengaruhi oleh beberapa faktor lainnya, yaitu gaya kepemimpinan melayani, penelitian yang dilakukan oleh Mahessa, dkk., (2016) kepada 24 orang karyawan BPJS ketenagakerjaan menunjukkan adanya hubungan yang positif yang signifikan antara gaya kepemimpinan melayani dengan readiness for change; komitmen organisasi menjadi salah satu faktor yang mempengaruhi readiness for change. Penelitian yang dilakukan oleh Pramadini, dkk., (2012) pada 72 orang karyawan Divisi Enterprise Service (DES) Telkom Kelintang Surabaya menunjukkan bahwa terdapat hubungan signifikan antara komitmen organisasi khususnya komitmen afektif dan 
komitmen normatif dengan readiness for change; Perceived Organizational Support, penelitian yang dilakukan oleh Dharmawan, dkk., (2017) membuktikan bahwa ada hubungan positif yang signifikan antara perceived organizational support dengan readiness for change

Leader Member Exchange juga merupakan faktor yang mempengaruhi readiness for change, terbukti melalui penelitian yang dilakukan oleh Veronika, dkk., (2017), pada 67 pegawai Universitas Tidar di Magelang yang menunjukkan adanya hubungan positif dan signifikan antara leadermember exchange dengan readiness for change yang berarti semakin tinggi leadermember exchange maka semakin tinggi readiness for change. Selain itu, penelitian lain yang dilakukan oleh Afriani, dkk., (2014), terhadap 121 pekerja pada PT. Pertamina EP Asset 3 (tiga) Field Jatibarang, menunjukkan adanya hubungan positif antara persepsi terhadap kepemimpinan resonan dengan readiness for change, artinya jika adanya persepsi terhadap kepemimpinan dalam suatu perusahan akan membuat karyawan siap untuk berubah.

Berdasarkan dari semua uraian di atas, peneliti sangat tertarik dalam melakukan penelitian untuk mengetahui hubungan kepemimpinan transformasional dengan readiness for change pada karyawan PT. Mega Anugerah Mandiri Medan. Adapun hipotesis yang diajukan dalam penelitian ini adalah "Adanya hubungan positif antara kepemimpinan transformasional dengan readiness for change", yang artinya semakin tinggi kepemimpinan transformasional, maka readiness for change seseorang akan meningkat, sebaliknya jika kepemimpinan transformasional rendah maka readiness for change seseorang juga menurun. Manfaat atau pentingnya dari penelitian ini yaitu diharapkan dapat membuat pemimpin menjadi lebih maksimal dalam memberikan dukungan, peduli terhadap karyawan, menjalin hubungan yang baik, memberikan arah kepada karyawan untuk mencapai tujuan yang telah ditetapkan oleh perusahaan, sehingga perusahaan bisa terus maju dan berkembang sesuai dengan perubahan zaman, sebagai wujud kepemimpinan transformasional.

\section{Metode}

\section{Subjek}

Subjek dalam penelitian ini adalah karyawan/I PT. Mega Anugerah Mandiri. Melihat jumlah populasi yang relatif kecil, yakni 120 orang, maka teknik pengambilan sampel yang digunakan adalah total sampling (sampling jenuh), yakni teknik penentuan sampel bila semua anggota populasi digunakan sebagai sampel (Sugiyono, 2010). Jumlah sampel yang akan digunakan dalam penelitian ini adalah keseluruhan populasi yaitu karyawan-karyawan PT. Mega Anugerah Mandiri Medan yang berjumlah 120 orang. Adapun karakteristik sampel adalah sebagai berikut :

a. Karyawan tetap PT. Mega Anugrah Mandiri.

b. Karyawan yang telah bekerja minimal 1 tahun.

c. Karyawan yang telah berusia minimal 20 tahun.

\section{Pengukuran}

Alat pengumpul data yang digunakan dalam penelitian ini adalah dengan menggunakan metode skala. Effendi (dalam Singarimbun \& Effendi 2006), menyatakan bahwa skala merupakan ukuran gabungan buat suatu variabel atau ukuran gabungan yang didasarkan pada struktur intensitas 
pertanyaan-pertanyaan, skala disusun atas dasar penujukkan skor pada polapola atribut yang berarti dalam penyusunan skala diperhatikan intesitas struktur dari atribut-atribut yang hendak diukur. Alasan digunakannya skala adalah dapat mengurutkan responden-responden ke dalam urutan ordinal dengan lebih tepat karena dalam proses tersebut diperhatikan intensitas bobot dari tiap pertanyaan (Effendi, dalam Singarimbun \& Effendi, 2006).

Penelitian ini menggunakan dua skala yaitu skala readiness for change dan skala kepemimpinan transformasional. Skala yang digunakan dalam penelitian ini disajikan dalam bentuk pernyataan yang bersifat favourable dan unfavorable dengan empat alternatif jawaban untuk setiap empat butir pernyataan. Kriteria penilaian aitem favourable berdasarkan skala Likert adalah nilai 1 (satu) untuk jawaban Sangat Tidak Setuju (STS), nilai 2 (dua) untuk jawaban Tidak Setuju (TS), nilai 3 (tiga) untuk jawaban Setuju (S), dan nilai 4 (empat) untuk jawaban Sangat Setuju (SS). Sedangkan untuk aitem unfavourable, nilai 1 (satu) untuk jawaban Sangat Setuju (SS), nilai 2 (dua) untuk jawaban Setuju (S), nilai 3 (tiga) untuk jawaban Tidak Setuju (TS) dan nilai 4 (empat) untuk jawaban Sangat Tidak Setuju (STS) yang disebut dengan skala Likert (Effendi, dalam Singarimbun \& Effendi, 2006).

Adapun empat pilihan jawaban dipakai dalam penyusunan skala ini adalah untuk menghindari kemungkinan jawaban di tengah-tengah. Subjek diminta untuk memilih salah satu dari keempat alternatif jawaban yang tersedia yang sesuai dengan keadaan subjek. Penelitian ini menggunakan dua skala yaitu skala Readiness for Change dan skala Kepemimpinan Transformasional.

Skala readiness for change disusun berdasarkan teori yang dikembangkan oleh Armenakis dan Harris (2009), untuk mengukur readiness for chanage, yang terdiri dari lima aspek antara lain arti aspek discrepancy, aspek appropiateness, aspek efficacy, aspek principal support, dan aspek personal valence. Sedangkan skala kepemimpinan transformasional disusun berdasarkan teori yang dikembangkan oleh Robbins dan Judge (2007) yang terdiri dari empat aspek kepemimpinan transformasional antara lain aspek pengaruh yang ideal, motivasi yang inspirasional, stimulasi intelektual, pertimbangan yang bersifat individual.

Hasil Uji Validitas dan Reliabilitas Alat Ukur

Pelaksanaan uji validitas dan reliabilitas alatukur dilakukan padakaryawan/IPT.Calispo Multi Utama Medan. Sebanyak 85 karyawan PT.Calispo Multi Utama Medan menjadi sampel. Pemilihan subjek pada perusahaan ini didasarkan karena fenomena yang diperoleh peneliti berasal dari perusahaan ini.

Pada skala readiness for change, hasil uji coba alat ukur menunjukkan bahwa 27 dari 50 aitem dinyatakan sahih. Uji validitas dalam tryout penelitian ini menggunakan metode corrected item total correlation dimana aitem yang valid dapat dilihat pada tabel corrected item total correlation berdasarkan $r$ minimal 0,3 dengan nilai $r$ bergerak dari 0.304-0.683. Dalam skala readiness for change ini diperoleh realibilitas Alpha Cronbach sebesar 0.884 . Dengan hasil ini diperoleh arti bahwa skala ini layak digunakan sebagai alat pengumpulan data dalam penelitian ini.

Pada skala kepemimpinan transformasional, hasil uji coba alat ukur menunjukkan bahwa 32 dari 48 aitem dinyatakan sahih. Uji validitas dalam tryout penelitian ini juga menggunakan metode corrected item total correlation dimana aitem yang valid 
dapat dilihat pada tabel corrected item total correlation berdasarkan $r$ minimal 0,3 dengan nilai $r$ bergerak dari 0.308-0.734. Dalam skala kepemimpinan transformasional ini diperoleh realibilitas Alpha Cronbach sebesar 0.953. Dengan hasil ini diperoleh arti bahwa skala ini layak digunakan sebagai alat pengumpulan data dalam penelitian ini.

\section{Hasil}

Metode analisis data yang digunakan dalam penelitian ini adalah korelasi Product Moment Pearson. Metode ini digunakan untuk mengetahui hubungan antara kedua variabel tersebut. Analisis korelasi ini menggunakan bantuan SPSS Statistics 20 for Windows.

Deskripsi data dalam penelitian ini mencakup skor empirik dan skor hipotetik. Skala Readiness for Change terdiri dari 27 aitem dengan skor aitemnya yang bergerak dari empat pilihan jawaban dengan skor satu sampai empat. Rentang maksimum dan minimumnya adalah $27 \times 1$ sampai $27 \times 4$, yaitu 27 sampai 108 dengan mean hipotetiknya $(27+108): 2=67.5$. Standar deviasi hipotetik dalam penelitian ini adalah (108-27) : $6=$ 13.5. Dari skala readiness for change yang diisi subjek, maka diperoleh mean empirik sebesar 79.85 dan standar deviasi sebesar 11.068. Hasil analisis untuk skala readiness for change diperoleh mean empirik > mean hipotetik yaitu $79.85>67.5$ maka dapat disimpulkan bahwa readiness for change pada subjek penelitian lebih tinggi daripada populasi pada umumnya.

Skala kepemimpinan transformasional terdiri dari 32 aitem dengan skor aitemnya yang bergerak dari empat pilihan jawaban dengan skor satu sampai empat. Rentang maksimum dan minimumnya adalah $32 \times 1$ sampai $32 \times 4$, yaitu 32 sampai 128 dengan mean hipotetiknya $(32+128): 2=80$. Standar deviasi hipotetik dalam penelitian ini adalah $(128-32): 6=16$. Dari skala kepemimpinan transformasional yang diisi subjek, maka diperoleh mean empirik sebesar 97.72 dan standar deviasi sebesar 13.293. Hasil analisis untuk skala kepemimpinan transformasional diperoleh mean empirik > mean hipotetik yaitu $97.73<80$ maka dapat disimpulkan bahwa kepemimpinan transformasional yang dimiliki subjek pada penelitian ini lebih tinggi daripada populasi pada umumnya.

Tabel 1. Perbandingan Data Empirik dan Hipotetik

\begin{tabular}{|c|c|c|c|c|c|c|c|c|}
\hline \multirow{2}{*}{ Variabel } & \multicolumn{3}{|c|}{ Empirik } & \multirow{2}{*}{ SD } & \multicolumn{3}{|c|}{ Hipotetik } & \multirow{2}{*}{ SD } \\
\hline & Min & Max & Mean & & Min & Max & Mean & \\
\hline $\begin{array}{c}\text { Readiness for } \\
\text { Change }\end{array}$ & 44 & 96 & 79.85 & 11.069 & 27 & 108 & 67.5 & 13.5 \\
\hline $\begin{array}{l}\text { Kepemimpinan } \\
\text { Transformasional }\end{array}$ & 60 & 122 & 97.73 & 13.294 & 32 & 128 & 80 & 16 \\
\hline
\end{tabular}

Selanjutnya subjek akan dibagi ke dalam tiga kategori readiness for change yaitu readiness for change rendah, sedang, dan tinggi. Standar deviasi hipotetik dalam penelitian ini adalah $\sigma=(108-27): 6=13.5$ dan mean hipotetiknya adalah $\mu=(27+108)$ :
$2=67.5$. Dari perhitungan di atas dapat dibuat perhitungannya berdasarkan rumus yang telah diuraikan di atas, diperoleh $\mathrm{x}<$ (67.513.5) $=x<54,(67.5-13.5) \leq x<(67.5+13.5)=$ $54 \leq x<81$ dan $x \geq(67 . .5+13.5)=x \geq 81$.

Sedangkan standar deviasi dalam 
penelitian kepemimpinan transformasional dapat dibuat perhitungannya berdasarkan hipotetik dalam penelitian ini adalah $\sigma=(128-$ rumus yang telah diuraikan di atas, diperoleh 32) : $6=16$ dan mean hipotetiknya adalah $\mu \quad x<(80-16)=x<64,(80-16) \leq x<(80+16)=$ $=(32+128): 2=80$. Dari perhitungan di atas $64 \leq x<96$ dan $x \geq(80+16)=x \geq 96$.

Tabel 2. Perbandingan Data Empirik dan Hipotetik

\begin{tabular}{ccccc}
\hline Variabel & Rentang Nilai & Kategori & Jumlah (n) & Persentase \\
\hline Readiness for & $x<54$ & Rendah & 6 & $5 \%$ \\
Change & $54 \leq x<81$ & Sedang & 58 & $48.33 \%$ \\
& $x \geq 81$ & Tinggi & 56 & $46.66 \%$ \\
& Jumlah & & 120 & $100 \%$ \\
Kepemimpinan & $x<64$ & Rendah & 2 & $1.66 \%$ \\
Transformasional & $64 \leq x<96$ & Sedang & 55 & $45.83 \%$ \\
& $x \geq 96$ & Tinggi & 63 & $52.5 \%$ \\
& Jumlah & & 120 & $100 \%$ \\
\hline
\end{tabular}

Uji Asumsi

Sebelum melakukan uji hipotesa, terlebih dahulu dilakukan uji asumsi untuk mengetahui ada tidaknya penyimpangan data yang diperoleh dari alat pengumpul data. Uji asumsi yang digunakan dalam penelitian ini adalah uji normalitas dan uji linearitas.

Uji Normalitas

Uji normalitas dilakukan agar dapat mengetahui apakah setiap data variabel penelitian telah menyebar secara normal atau tidak. Uji normalitas sebaran dalam penelitian ini diuji dengan menggunakan uji Kolmogorov Smirnov Test. Data dikatakan berdistribusi normal jika $p>0.05$ (Priyatno, 2011). Uji normalitas pada variabel readiness for change diperoleh koefisien KS-Z $=0.916$ dengan Sig sebesar 0.371 untuk uji 2 (dua) arah (two tailed) dan sedangkan penelitian ini memiliki hipotesis satu arah, sehingga yang dipakai adalah uji 1 (satu) ekor/ Sig 1-tailed sebesar 0.185 ( $p$ > 0.05), yang memiliki arti bahwa data pada variabel readiness for change memiliki sebaran atau berdistribusi normal. Uji normalitas yang dilakukan terhadap variabel kepemimpinan transformasional diperoleh koefisien KS-Z = 1.084 dengan Sig sebesar 0.190 untuk uji 2 (dua) arah (two tailed), dan Sig sebesar 0.095 untuk uji 1 (satu) arah ( $p$ $>0.05$ ), yang memiliki arti bahwa data pada variabel kepemimpinan transformasional memiliki sebaran atau berdistribusi normal.

Tabel 3. Hasil Uji Normalitas

\begin{tabular}{cccccc}
\hline Variabel & SD & KS-Z & Sig. & $\mathbf{P}$ & Keterangan \\
\hline $\begin{array}{c}\text { Readiness for } \\
\text { Change }\end{array}$ & 11.069 & 0.916 & 0.185 & $\mathrm{p}>0.05$ & Sebaran normal \\
$\begin{array}{c}\text { Kepemimpinan } \\
\text { Transformasional }\end{array}$ & 13.294 & 1.084 & 0.095 & $\mathrm{P}>0.05$ & Sebaran normal \\
\hline
\end{tabular}




\section{Uji Linearitas}

Ujilinearitasdigunakanuntukmengetahui apakah distribusi data penelitian yaitu variabel readiness for change dan kepemimpinan transformasional memiliki hubungan linear uji F (Anova). Variabel readiness for change dan kepemimpinan transformasional dikatakan memiliki hubungan linear jika $p<0.05$. Hasil uji linearitas pada penelitian ini diperoleh nilai signifikansi yaitu 0.000 maka $p<0.05$, dapat disimpulkan bahwa kedua variabel memiliki hubungan linear dan telah memenuhi syarat untuk dilakukan analisa korelasi Product Moment.

Uji Hipotesis

Hipotesis dalam penelitian ini adalah adanyahubungan positifantara kepemimpinan transformasional dengan readiness for change. Berdasarkan tujuan penelitian maka dilakukan uji Pearson Correlation.

Tabel 4. Linearitas dan Korelasi Readiness for Change dan Kepemimpinan Transformasional

\begin{tabular}{cccc}
\hline Variabel & F & Sig & Keterangan \\
\hline $\begin{array}{c}\text { Kepemimpinan Transformasional } \\
\text { Readiness for Change }\end{array}$ & 62.425 & 0.000 & Linear \\
\hline \multicolumn{3}{c}{ Pearson Correlation } & Signifikansi $(p)$ \\
\hline Analisis & 0.571 & 0.000
\end{tabular}

Berdasarkan hasil analisis korelasi antara kepemimpinan transformasional dengan readiness for change, diperoleh koefisien korelasi product moment sebesar 0.571 dengan sig sebesar $0.000(p<0.05)$. Hasil tersebut menunjukkan bahwa adanya korelasi positif antara kepemimpinan transformasional dengan readiness for change sehingga dikategorikan hubungan yang cukup kuat (Priyatno, 2011). Dari hasil perhitungan tersebut, maka hipotesis yang diajukan dalam penelitian ini menunjukkan adanya hubungan positif antara kepemimpinan transformasional dengan readiness for change.

\section{Pembahasan}

Hasil penelitian pada 120 karyawan PT. Mega Anugrah Mandiri yang menjadi subjek penelitian, diperoleh hasil bahwa ada hubungan antara kepemimpinan transformasional dengan readiness for change dengan koefisien korelasi Product
Moment sebesar $r=0.571$ dan nilai $p=$ 0.000 , artinya semakin tinggi kepemimpinan transformasional maka semakin tinggi readiness for change, dan sebaliknya semakin rendah kepemimpinan transformasional maka semakin tinggi readiness for change.

Hasil penelitian yang menyatakan adanya hubungan antara kepemimpinan transformasional dengan readiness for change sejalan dengan pendapat Fitrianna, dkk., (2012), yang menyatakan bahwa salah kepemimpinan transformasional sangat sesuai untuk membawa perubahan, sebagai bahan penelitian tentang konteks perubahan, mampu menjelaskan lebih detail terkait dengan peran kepemimpinan transformasional dalam setiap dimensinya dan mencerminkan dengan kondisi lapangan yang organisasi sedang mengalami perubahan dan dibutuhkan sosok kepemimpinan transformasional di dalamnya. Dalam hal ini kepemimpinan trasnsformasional akan meningkatkan inovasi organisasi secara 
langsung dengan menciptakan visi dan secara tidak langsung dapat menciptakan lingkungan yang mendukung eksplorasi, eksperimen, berani mengambil resiko, dan berbagi ide.

Adapun hasil penelitian ini juga sejalan dengan penelitian yang dilakukan oleh beberapa peneliti lain seperti Abbasi (2017), yang menunjukkan adanya hubungan positif yang signifikan antara kepemimpinan transformasional dengan readiness for change seseorang. Dengan adanya gaya kepemimpinan transformasional di suatu perusahaan maka karyawan mampu siap untuk mengalami perubahan yang terjadi di perusahaan.

Penelitian ini menunjukkan ada 6 (enam) orang anggota dengan persentase 5 persen yang berada pada kategori readiness for change rendah, kemudian 58 anggota dengan persentase 48.33 persen termasuk ke dalam kategori sedang dan terdapat 56 anggota yang dikategorikan memiliki readiness for change yang tinggi dengan persentase sebesar 46.66 persen. Berdasarkan penjelasan di atas dapat disimpulkan rata-rata karyawan PT. Mega Anugrah Mandiri memiliki readiness for change yang sedang.

Berdasarkan hasil observasi dan wawancara terhadap pemimpin dan karyawan di PT. Mega Anugrah Mandiri menunjukkan readiness for change yang rendah dengan persentase 5 persen terlihat dari dimensi efficacy yaitu rasa kepercayaan bahwa karyawan dan organisasi mampu mengimplementasikan perubahan. Beberapa karyawan merasa tidak mampu mengikuti perubahan yang terjadi. Hal ini terlihat dari cari kerja mereka yang sering melanggar peraturan sistem kerja yang baru. Serta dimensi personal valence yaitu karyawan bisa merasakan keuntungan personal yang akan didapatkannya dari perubahan yang terjadi di perusahaan seperti beban kerja yang semakin menurun. Karyawan merasa tidak perlu melakukan perubahan karena mereka tidak merasa adanya perkembangan yang terjadi setelah dilakukan perubahan tersebut.

Dalam data penelitian ini juga diperoleh hasil sebanyak 58 anggota dengan persentase 48.33 persen yang dikategorikan memiliki readiness for change sedang. Hasil ini sesuai dengan adanya sebagian karyawan yang mencoba untuk mengikuti perubahan yang terjadi di perusahaan dan berusaha untuk menjalankannya sesuai arahan dari pimpinan dan mendapatkan motivasi dari pimpinan agar dapat mengikuti perubahan yang terjadi. Pernyataan di atas sesuai dengan dimensi principal support yaitu pimpinan memberikan dukungan dan berkomitmen dalam pelaksanaan perubahan dan menyukseskan perubahan organisasi.

Sisanya ada 56 anggota yang dikategorikan memiliki readiness for change yang tinggi dengan persentase 46.66 persen. Hasil ini dapat diungkapkan dimana sebagian karyawan telah siap menjalani perubahan dan telah terbiasa dengan perubahan yang terjadi sehingga mereka dapat bekerja dengan baik dan merasakan adanya manfaat yang diperoleh dari perubahan yang terjadi di perusahaan. Pernyataan tersebut mewakili dimensi dari readiness for change yaitu personal valence dan efficacy.

Penelitian ini menunjukkan rata-rata karyawan PT. Mega Anugrah Mandiri memiliki kepemimpinan transformasional yang tinggi, ini dapat dilihat dari data penelitian terdapat 2 karyawan dengan persentase 1.66 persen yang dikategorikan kepemimpinan transformasional rendah, kemudian terdapat 55 karyawan yang dikategorikan memiliki kepemimpinan transformasional yang sedang dengan persentase sebesar 45.83 persen, 
dan sebanyak 63 karyawan dikategorikan memiliki kepemimpinan transformasional tinggi dengan persentase 52.5 persen.

Anggota yang memiliki persentase 1.66 persen memiliki kepemimpinan transformasional yang rendah, ini dapat diungkapkan melalui aspek motivasi yang inspirasional dimana karyawan merasa tidak termotivasi dengan pemimpin mereka. Karyawan tidak semangat bekerja dan prestasi kerja mereka sangat tidak bagus dibandingkan dengan karyawan lainnya.

Dari hasil penelitian ini juga diperoleh data sebesar 45.83 persen dengan jumlah 55 karyawan yang dikategorikan memiliki kepemimpinan transformasional sedang yang terlihat dari aspek pertimbangan yang bersifat individual. Karyawan merasa hasil kerja keras mereka dihargai dan pimpinan mereka juga mau mendengarkan ide dari bawahannya.

Data penelitian juga menunjukkan bahwa 63 anggota memiliki kepemimpinan transformasional yang tinggi dengan persentase sebesar 63 persen, ini terlihat dari aspek motiasi inspirasional dimana karyawan sangat termotivasi untuk bekerja dengan baik dan mampu mengikuti perubahan yang terjadi di perusahaan. Aspek pengaruh yang ideal tercemin dari perilaku pimpinan mereka yang tidak melanggar peraturan dan memberikan contoh yang baik kepada bawahannya sehingga bawahannya menjadikan pimpinan mereka sebagai panutan mereka. Sebagian karyawan disana juga jarang melakukan pelanggaran aturan yang telah ditetapkan oleh perusahaan.

Berdasarkan penjelasan di atas maka dapat dikatakan kepemimpinan transformasional dapat meningkatkan tingkat readinessforchangepadakaryawan.Sehingga dapat disimpulkan bahwa ada hubungan positif antara kepemimpinan transformasional dengan readiness for change. Semakin tinggi kepemimpinan transformasional, maka semakin tinggi tingkat readiness for change karyawan, dan sebaliknya semakin rendah kepemimpinan transformasional yang dimiliki maka semakin rendah tingkat readiness for change yang dimiliki.

\section{Kesimpulan}

Kesimpulan dari penelitian ini adalah terdapat hubungan positif yang signifikan antara kepemimpinan transformasional dengan readinessforchange. Hal ini dibuktikan dengan nilai koefisien kolerasi Product Moment (Pearson Correlation) ( $r$ ) sebesar 0.571 dengan $p$ sebesar $0.000(p<0.05)$, yang artinya semakin tinggi kepemimpinan transformasional, maka akan semakin tinggi readiness for change karyawan, dan sebaliknyajika semakin rendah kepemimpinan transformasional, maka semakin rendah pula readiness for change pada karyawan.

\section{Daftar Pustaka}

Abbasi, B. (2017). Transformational Leadership and Change Readiness and a Moderating Role of Perceived Bureaucratic Structure: an Empirical Investigation. Problems and Perspective in Management. Vol 15. https://businessperspectives.org/ journals/problems-and-perspectivesin-management/issues-1-contents/ transformasional-leadership-andchange-readiness-and-a-moderatingrole-of-perceived-bureaucraticstructure-an-empirical-investigation..

Afriani, D, \& Prihatsanti, U. (2014). Hubungan antara Persepsi Terhadap Kepemimpinan Resonan dengan Kesiapan untuk Berubah. Jurnal Psikologi Universitas Diponegoro. Vol 3(2). diterima dari https://ejournal3. undip.ac.id/index.php/empati/article/ view/7506.

Ancok, D. (2012). Psikologi Kepemimpinan dan Inovasi. Jakarta: Penerbit Erlangga.

Armenakis \& Harris. (2009). Improving 
Organizational Intervensions for Stress and Well-Being. USA and Canada: Routledge.

Dharmawan, C,. \& Nurtjahjanti, H. (2017). Hubungan antara Perceived Organizational Support dan Kesiapan untuk Berubah. Jurnal Empati. Vol 6(1).diterima dari https://www.neliti. com/id/publications/70861/hubunganantara-perceived-organizationalsupport-dan-kesiapan-untuk-berubah.

Fitrianna, Nurma, Agustina, \& Tri Siwi. (2015). Transformational Leadership and Commitement to Change: Dimediasi oleh Readiness for Change. Jurnal Manajemen Bisnis Indonesia. Vol 2 No 2.dari http://fmi.or.id/jmbi/index. php/jurnal/article/view/47.

Holt. (2007). Change Lessons From The CEO: Real People Real Change. San Fransisco CA: Jossey-Bass.

Mahessa, F,. \& Frieda, N. (2016). Gaya Kepemimpinan Melayanidan Kesiapan untuk Berubah. Jurnal Empati. Vol 5(1). Diterima dari https://ejournal3. undip.ac.id/index.php/empati/article/ view/15066.

Mulyadi. (2007). Perilaku Organisasi. Yogyakarta: Deepublish

Northouse, P.G. (2013). Kepemimpinan Teori dan Praktik. Edisi Keenam. Jakarta: Indeks.

Pramadini, B,. \& Fajrianthi. (2012). Hubungan antara Komitmen Organisasi dengan Kesiapan untuk Berubah. Jurnal Psikologi Industri dan Organisasi. Dari Vol 1(02). journal.unair.ac.id/ filerPDF/110810026 7v.pdf.

Pramudianto. (2015). I'm a Coach: Strategi Mengembangkan Potensi Diri dengan Coaching. Yogyakarta: ANDI.

Pranowo, W,. \& Prihatsanti, U. (2016). HubunganAntara GayaKepemimpinan Transformasional dengan Kesiapan untuk Berubah pada Karyawan KPP Pratama Purworejo dan Temanggung DJP Wilayah Jawa Tengah II. Jurnal Empati. Volume 5(4). https://media. neliti.com/media/publications/62453ID-hubungan-antara-gayakepemimpinan-transf.pdf.

Priyatno, D. (2010). Teknik Mudah dan Cepat Melakukan Analisis Data Penelitian dengan SPSS. Yogyakarta : Gaya Media

Robbins, S.P. \& Judge, T. (2007). Perilaku Organisasi Buku 1. Jakarta: Salemba Empat.

Robbins, S.P. \& Judge, T. (2007). Perilaku Organisasi Buku 2. Jakarta: Salemba Empat.

Russell, J,. \& Russell, L. (2006). Change Basics. United States of America: Victor Graphics.

Sims, R.R. (2002). Organizational Success Through Effective Human Resources Management. United State of America: Quorum Books.

Singarimbun, M,. \& Effendi, S. (2006). Edisi

Revisi Metode Penelitian Survai.

Research Methods. Jakarta : LP3ES.

Sugiyono. (2012). Metode Penelitian

Pendidikan, Pendekatan Kuantitatif, Kualitatif, dan R\&D. Bandung : Alfabeta.

Veronica, T,. \& Prihatsanti, U. (2017). Hubungan antara Leader Member Exchange dengan Kesiapan untuk Berubah. Jurnal Empati. Volume 6(1). https://ejournal3.undip.ac.id/index. php/empati/article/.../14666. 